\title{
Humanoid Robot Enhancing Social and Communicate Skills of Autistic Children: Review
}

\author{
S.M. Shadman Shahriar ${ }^{1}$, Al-Waddah Al-Abdulsalam ${ }^{1}$, Khalil Ibrahim Al-Farsi ${ }^{1}$, and Mohammed J. Yousif ${ }^{2, *}$ \\ ${ }^{1}$ Faculty of Computing \& Information Technology, Sohar University, Oman. \\ ${ }^{2}$ Department of Computer Science, Faculty of Science, Memorial University \\ *Corresponding author: Mohammed J. Yousif, mohyou200210@gmail.com
}

\begin{abstract}
Autism is a neurological disease that affects people's social, communicational, and mental abilities. This makes it difficult for them to express themselves and integrate seamlessly with other people and society as a whole. With the number of autism cases steadily increasing, researchers and caretakers alike worldwide are working on finding a teaching technique to help with the therapy and education of autistic children. Due to the number of resources and expertise required for this operation, it has proven quite challenging to find such a teaching technique. The results of our literature survey also show that the USA has the most research in this field, followed by England and Spain. This paper aims to study the interaction of autistic children with the humanoid robot NAO. Therefore, we developed different interactive activities and materials for testing the children's attitude and engagement. After careful observation and experimenting, it was found that the children were much more engaged and excited during the lessons that involved the robot. This can be attributed to its simple and toy-like nature, making the lessons more fun and exciting. The children were also more responsive, absorbed more information overall, and were even willing to learn new subjects that they previously avoided.
\end{abstract}

Keywords: autism spectrum disorders; teaching by robot; robot NAO; human-robot interaction 


\section{Introduction}

Autism spectrum disorders (ASD) complicate neurodevelopmental diseases with strong genetic etiologies. While many brain regions associated with ASD pathogenesis, many studies demonstrate that the cerebellum is consistently abnormal in ASD patients, both neuron and functionally. Estimated total costs per year for autistic children in the United States, for example, are between $\$ 11.5$ billion - \$ 60.9 billion (2011 US \$). Which represents a significant economic burden for direct and indirect costs, from medical care to private education (Vellonen et al., 2012).

Humanoid robot frequently has the inherent to interact with people in daily life (Shamsuddin et al., 2012). They can play an essential role in human society in the future. The new development of human-robot interaction (HRI) is now extending its functions to assist the children suffering from Autism Spectrum Disorders (ASD) in areas of socialization, communication, and playful behavior through robot-based intervention (Robins et al., 2004). HRI architecture considers as a new approach to the research on autism. HRI defines as a communication relationship between humans and humanoid robots. Nearly about third of children with autism seem to miss skills in their second year. Approximately 6 per 1000 children under eight years have ASD. Different Methodology uses to act with ASD including studies, diagnostic practice, and an expert (Robins et al., 2009). Many researchers conclude that ASDs have a difference of causes, but they agree that ASD affects the same brain systems (Miskam et al., 2014; Malik et al., 2014). Moreover, the interview and observational methods have clear advantages and disadvantages. Retrospective reporting may be hard for parents of older offspring. The observations in clinical environments can miss critical features. An acceptable approach would combine an interview and observational measures.

Autism is a disease, which affects the child's ability to communicate with those around him and develop mutual relations with them. The prevalence of ASD is around 1\%, and recent estimation of undiagnosed cases increases it to $1.5 \%$ in the UK (Baron-Cohen et al., 2009). Also, about one-third of parents of children with ASD noticed a problem before their Childs first birthday, and $80 \%$ saw problems by 24 months. The earliest age of ASD diagnosis is between 4.5 and 5.5 years. ASD incidence dramatically depends on gender, therefore; about four times more boys have autism than girls. In the United States, statistics denote that a child in every 91 children diagnoses with ASD. Moreover, in Malaysia, a child in every 150 children has ASD problem. The increasing prevalence of ASD in different countries all over the world, it is understandable that the need for effective intervention for ASD to be classified as a public health emergency. Figure 1 shows the autism statistics prevalence of children. Statistics show an annual increase of 
the disease about 1 child of 59 in 2018 has with autism in world in comparison of 1 child of 1000 in 1970. Despite differences in the seriousness of the symptoms of autism from case to case, but the patients with autism have difficulties in their mutual social relations, language, and behavior.

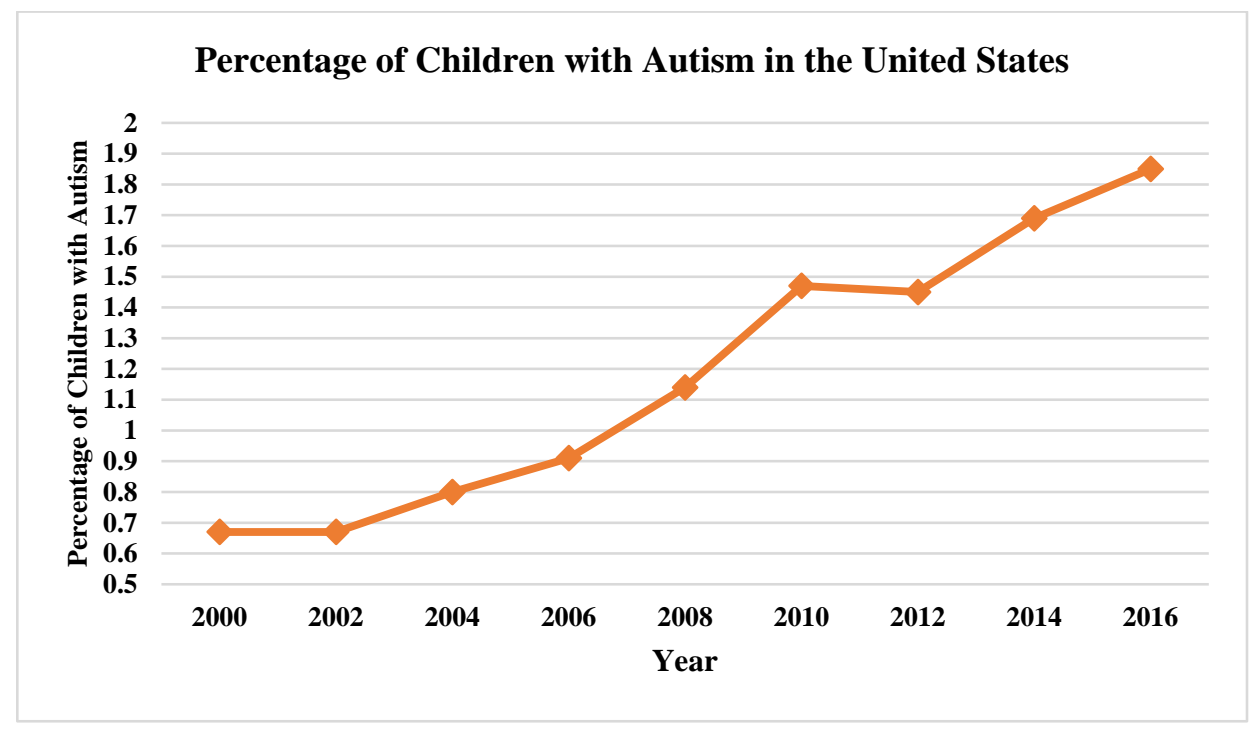

Figure 1. The autism statistics prevalence of children (Tacanow, 2021)

Many studies were discussed and proposed solution for teaching and learning kids with Autism. They implemented different methods. Table 1 presents the main approaches for teaching kids with Autism.

Table 1. survey of research papers and methods of ASD

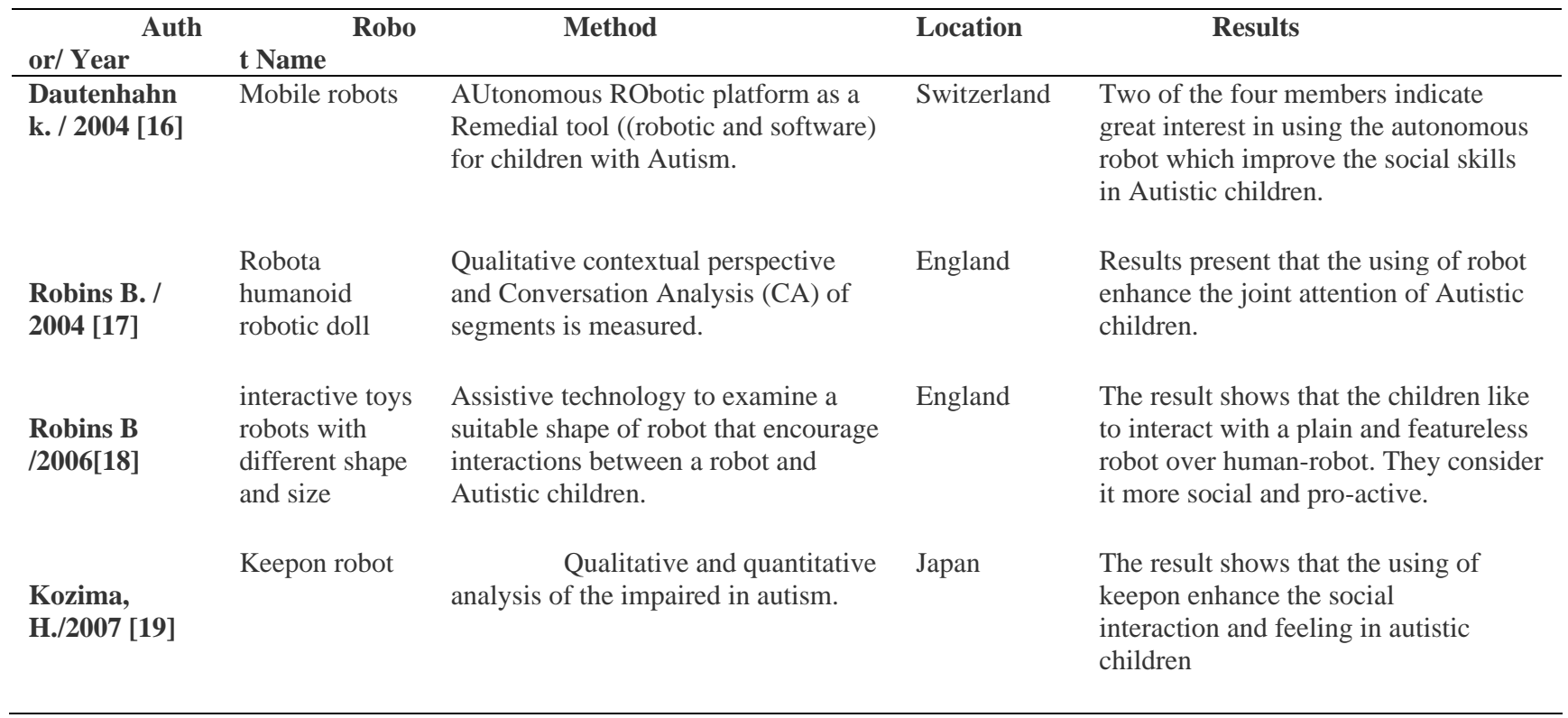




\begin{tabular}{lll}
\hline Pierno, A.C & $\begin{array}{l}\text { Human or a } \\
\text { robotic arm } \\
\text { model }\end{array}$ & $\begin{array}{l}\text { Observe the performance of autistic } \\
\text { children with a robotic arm model or }\end{array}$ \\
& human model performing well.
\end{tabular}

Stanton C.M $/ 2008$ [21]

AIBO Dog
robot

Duquette A /2008 [22]

De Silva, / 2009 [23]

\section{Feil-Seifer / Socially 2009 [24] Assistive Robotics}

Mobile robot

Stribling P. / platform 2009[25]

Francois D. / 2009[26]

Lund H. H. / 2009 [27]

$\begin{array}{ll}\text { Costa, S. I } & \text { LEGO } \\ \mathbf{2 0 1 0}[\mathbf{2 8}] & \begin{array}{l}\text { MindStorm } \\ \text { robot }\end{array}\end{array}$

$\begin{array}{ll}\text { Wainer, J } & \text { programmed } \\ / \mathbf{2 0 1 0}[\mathbf{2 9}] & \text { Lego robots }\end{array}$

Comparison study between the responses to using of Robotic Dog versus Mechanical Toy Dog (Kasha).

Conduct an exploratory study with four children for testing how the mobile robot is more predictable, attractive and easy than a human being.

An unsupervised Mixture Gaussianintention.

Design and implement robot systems to act as catalysts for social behavior for ASD therapy.

Conversation analysis is used to examine the typical/repetitive speech caused by the robot.

Design, conduct and analyses robotassisted play with non-mandate interference with the processor, incorporated a mechanical dog in the room that reacted to touch. of the diversion utilizing mechanical tiles and modules to recognize every kid utilizing a neural system display.

The two members separately took an interest with the robot in a basic passing ballgame, with each other, and also with the robot based Four scenarios.

Members took an interest in mechanical technology class, apply autonomy customized, and worked with peers who additionally have ASD. based cluster method to assess kid's

Client's reactions are utilized as a part
USA

Japan.

Canada

England

USA

Spain

England.

USA class to increase the social interactions.
Many Kids were delighted in classes, teamed up with peers in class, and proceeded with cooperation even after class. They found their experiences in

The results demonstrate that the children with autism shown faster movement when using robots. Also, the visuomotor priming processes are enhanced.

Kids interact and spoke more words to AIBO and enhancing three behaviors like verbal engagement, reciprocal interaction, and authentic interaction.

Two children engage with a robot mediator determine increased attention in visual contact and physical proximity and in imitating smiling more than the children examine with the human.

Create engagement between the child and robot for building a learning environment for autistic children. Results show that the kids liked interaction with the robot, which used as mediator of joint attention.

The results show that the robot socially assistive in a therapeutic setting for kids with ASD and they interacting with a robot.

Analysis of the boy's talking on a specific topic and used the robot to extract a typical/monotonous of speech.

Cases were analyzed and demonstrated individually based three directions Play, Reasoning and Affect. The evaluation shows that kids are interested in the robot and socially progressively.

Neural system shows effectively distinguished emotionally positive social interaction in individual imitative behavioral examples of autistic kids with $88 \%$ exactness.

An increase in association with robot and improve the social interaction and communication of youths with both autism and mental impairment. 


\begin{tabular}{lll}
\hline $\begin{array}{l}\text { Feil-Seifer \& } \\
\text { Matarić /2011 } \\
\text { [30] }\end{array}$ & $\begin{array}{l}\text { Robot- } \\
\text { augmented } \\
\text { based } \\
\text { DIR/Floortime } \\
\text { intervention. }\end{array}$ & $\begin{array}{l}\text { Measure the positive and negative } \\
\text { feedback of the robot that the reaction } \\
\text { depends on behavior of the participant }\end{array}$ \\
$\begin{array}{l}\text { Shamsuddin, } \\
\text { S. / 2012[31] }\end{array}$ & NAO robot & The applications of robots (NAO) \\
for possible intervention methods
\end{tabular}

Costa, S. I

2015 [34]

Agosta, G., Borghese, et al. 2015 [35]

Supervised Smart Space (P3S)

Richard
Margolin/
2016 [36]

Haje Jan [37] Pepper Robot

Jeff Goodman MILO robot /2017 [38]

$\begin{array}{ll}\text { Huijnen, } & \text { NAO, } \\ \text { C.A.G.J. /2017 } & \text { KASPAR, } \\ \text { [39] } & \text { Robota, Probo }\end{array}$

Spain

France

USA

Used KASPAR humanoid- robot to interact with autism children.

Discovers novel methods of using smart spaces to support full body interaction with smart objects.

Specialists who were selected to work in the program were shown how to use Milo, then works with the MILO robot and the coaches were seen through Webcam and were given feedback.

Pepper displays a flash card on its screen.

Using MILO robot to engage with children with autism and simulate the therapist instruction.

Review the using of different robots like NAO, KASPAR, Robota, Probo, for teach ASD children to perform a task.

Italy

USA

USA

USA
A great individual contrast in reacting to the robot, despite the circumstances. The robot increases the social behavior of a child

Present the clinical applications of robots in therapy for children with autism. Proposed a guidelines role and procedures to serve researchers and parents.

A robot-child interaction is established as a mediator to express positive emotion playing with the therapist.

Research shows that the children with autism fully interacted more with the humanoid robot. Applied Behavioral Analysis therapy where the child interacts with a tablet computer wirelessly interfaced with the robot.

KASPAR robot helps Autistic kids between four and fourteen years old boosted body awareness and sense of self, manage cooperative play and helping others to break their isolation.

Architecture and coordination infrastructure created in the Playful Supervised Smart Space.

Autism specialists who have worked with Milo's robot believe that it helped numerous kids to perceive and impart their sentiments, value-based and manage their feelings, apply calming aptitudes and two-sided discussion.

Results shows that robot help autistic children to enhance the concept of emotions and learning.

Researchers found that the autistic children are more involved with Milo's robot than with a physician.

Review the using of different type of robots for teaching ASD children a Social interaction and how to Communicate. 


\section{Text body Humanoid robot helps Autistic kids}

Many researchers have used artificial robots and new development of information technologies in many areas, including design, construction, operation, and education (Yousif, 2011). A Survey of prior studies has distinguished HRI as part of the intervention for children with ASD (Yousif et al., 2018; Yousif, 2021; Yousif, 2021; Adams et al., 2011; Ranatunga et al., 2011). This work aims to design a comprehensive Learning System Based humanoid robot for Children with Autism. Also, develop interactive materials that help children with special needs for enhancing their communicating and thinking. For example, teaching directions up, down, left, and right or responding to various commands such as sitting, standing, walking, and lifting objects after recognition and other actions. The child will communicate with the robot as a close-up game, which helps to increase the communication skills and accepting instructions fast.

A humanoid robot called NAO, developed by Softbank Robotics has been used to help the students' education, as shown in Figure 2. NAO is $58 \mathrm{~cm}$ tall and has several features that make it a standout among the wide variety of different methods that have been used to teach autistic children. With its ability to process 19 different languages, NAO can effectively provide lessons in all of these languages, which helps to increase accessibility to as many autistic students internationally as possible. There are many ways for human-robot interaction (HRI) to take place since NAO is equipped with cameras, microphones, speakers, and motors for physical movements. Using this equipment, NAO can walk, play, sing, stand, hold small objects, identify certain objects/people and understand as well as respond when spoken to in the appropriate language.

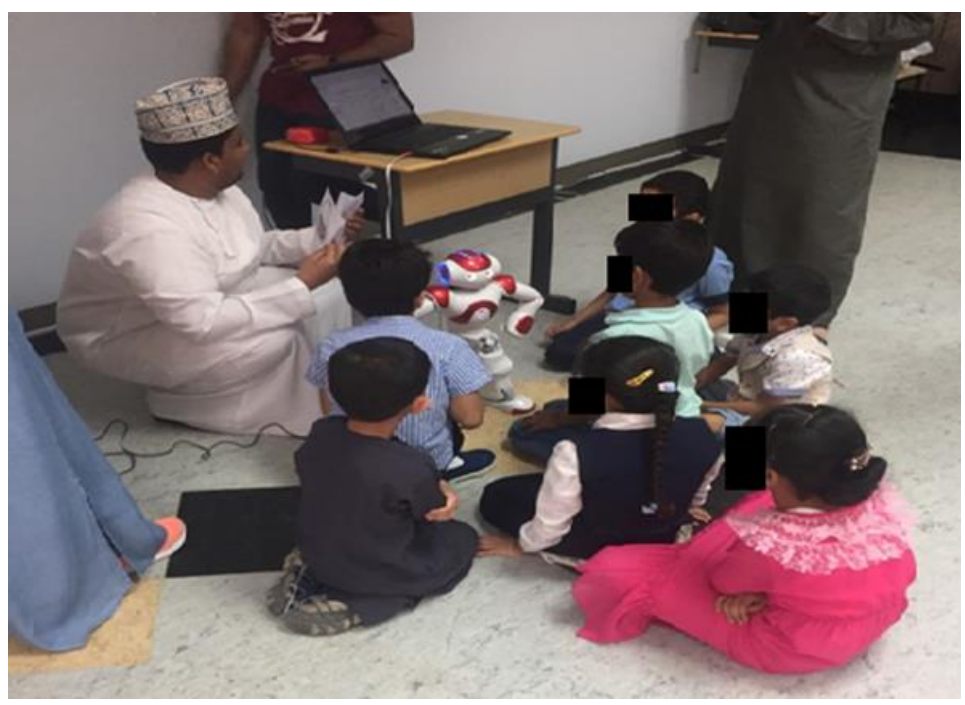

Figure 2. NAO robot in testing session 
Due to the robot's accessibility and extended functionality, it is no surprise that NAO is currently the most popular robot for use in research, education, and healthcare. There are, however, other robots that are used in these industries as well that can be seen in Table 1 .

\section{Problem Statement}

Statistics indicate that there was a significant increase (by 78\% over the last 4 years (Cabibihan et al., 2013)) in the number of kids with autism worldwide to 1 in 59 cases (TACA, 2016). This increase in the number of people infected with ASD should have a corresponding increase in handling and treating the patients. As well, the high cost of therapy in specialized centers is being a significant problem. Besides, teaching kids is not a trivial task. Thus, finding modern ways of using information technology and artificial intelligence is designed to develop intelligent robots to help children with psychological problems such as autism spectrum disorder, hyperactivity disorders, or lack of concentration are essential issues. These robots can be tested on children with autism spectrum in outpatient clinics under the direct supervision of pediatric specialists. Also, find a suitable method to communicate with kids and make practice the required duties are an essential concern. The new development of human-robot interaction (HRI) is now extending its functions to assist the children suffering from Autism Spectrum Disorders (ASD) in socialization, communication, and playful behavior through robot-based intervention. Therefore, this work aims to study and analyze previous studies of the existing system for using different types and shapes of robots in autistic children. Then use its results as a key for more research to choose suitable robots and methods to enhance the social and communication skills for kids with autism. The results will help to design and implement a framework for teaching Kids with Autism based robots.

\section{Proposed system Architecture}

This project will follow qualitative research methods to build a complete frame for teaching kids with Autism. The project is a multi-discipline which involves activities related to several fields of computing and information technology like the design and implements some interactive materials for kids who have a need.

The experimental phase will start with designing and implementing interactive materials for teaching and learning of kids with special needs. Then create and implement the framework for teaching children with autism-based NAO robot and C\# application. The framework will use these interactive teaching methods and classroom activities to motivated children with the autistic spectrum to improve their learning and attainment. Once the framework becomes 
ready for proper testing and evaluation by running sets of tests, and acquired results will be analyzed and discussed. Finally, adequate reporting of findings will be carried out. Figure 3 shows the proposed system Architecture that describes the interaction of outside entities with a system or subsystem. reliable.

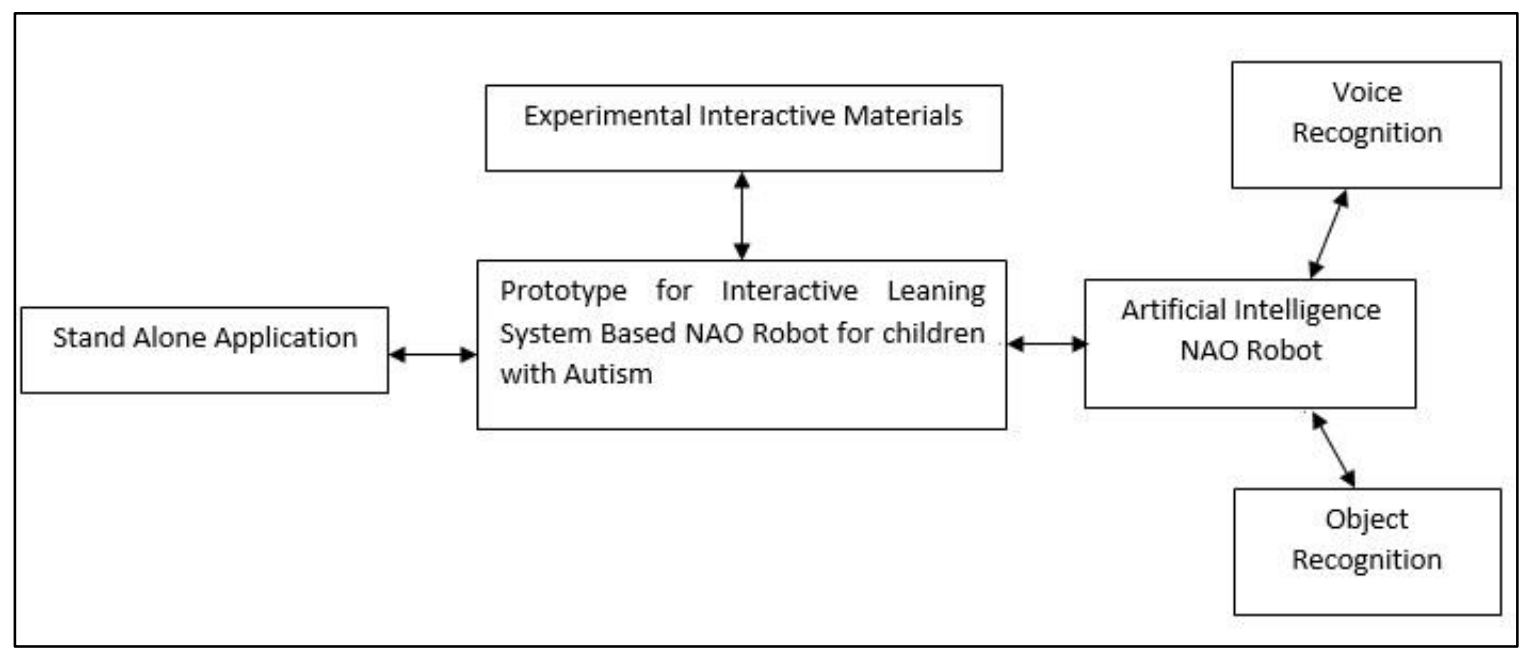

Figure 3. proposed system Architecture

\section{Learning System Implementation Using NAO Robot}

We have built several programs using the "Choregraphe" software that is bundled in with NAO. It is based on python, and it allows us to utilize all of NAO's features so that they can be incorporated in teaching lessons. Some of these features include speaking, listening, dancing, moving and playing. These applications have been built with both local and international users in mind, incorporating both Arabic and English to help make them accessible to as many children as possible. The NAO robot was used in this experiment due to its ease of programming and flexibility, allowing us to make countless different programs with a wide variety of scope and function. As example the Autism Information is performed using the voice recognition, which takes voice as input from the user and gives the right information asked by the user, as seen in Figure 4.

\subsection{Fruit recognition}

This program is developed for the users to learn about the fruits and recognize it. The robot explains a fruit and the user must choose the fruit and show it to the robot, the robot uses its camera to recognize the fruit and check it with whether the user have selected the right fruit or not. This can be seen in Figure 5. 


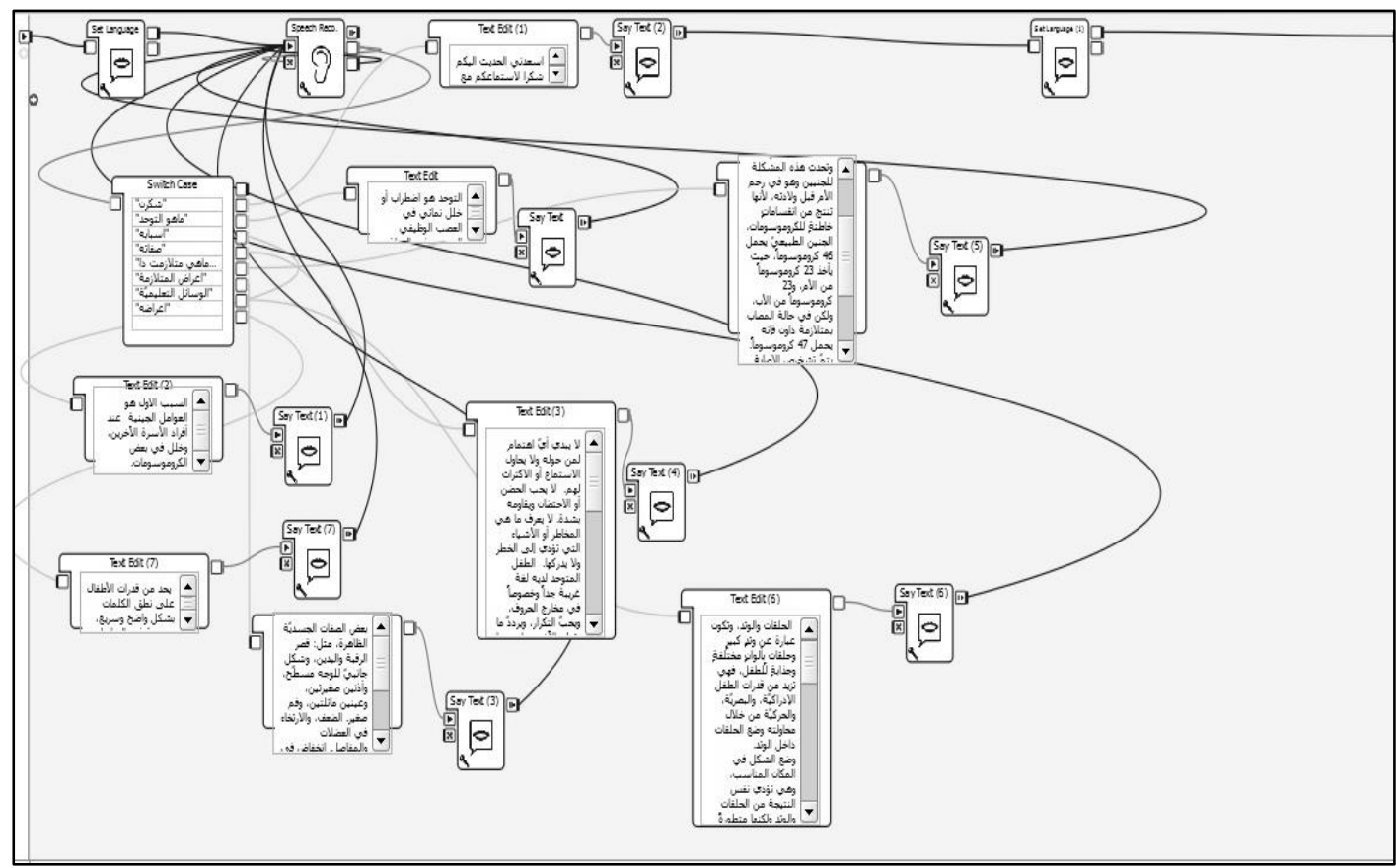

Figure 4. Autism Information Program

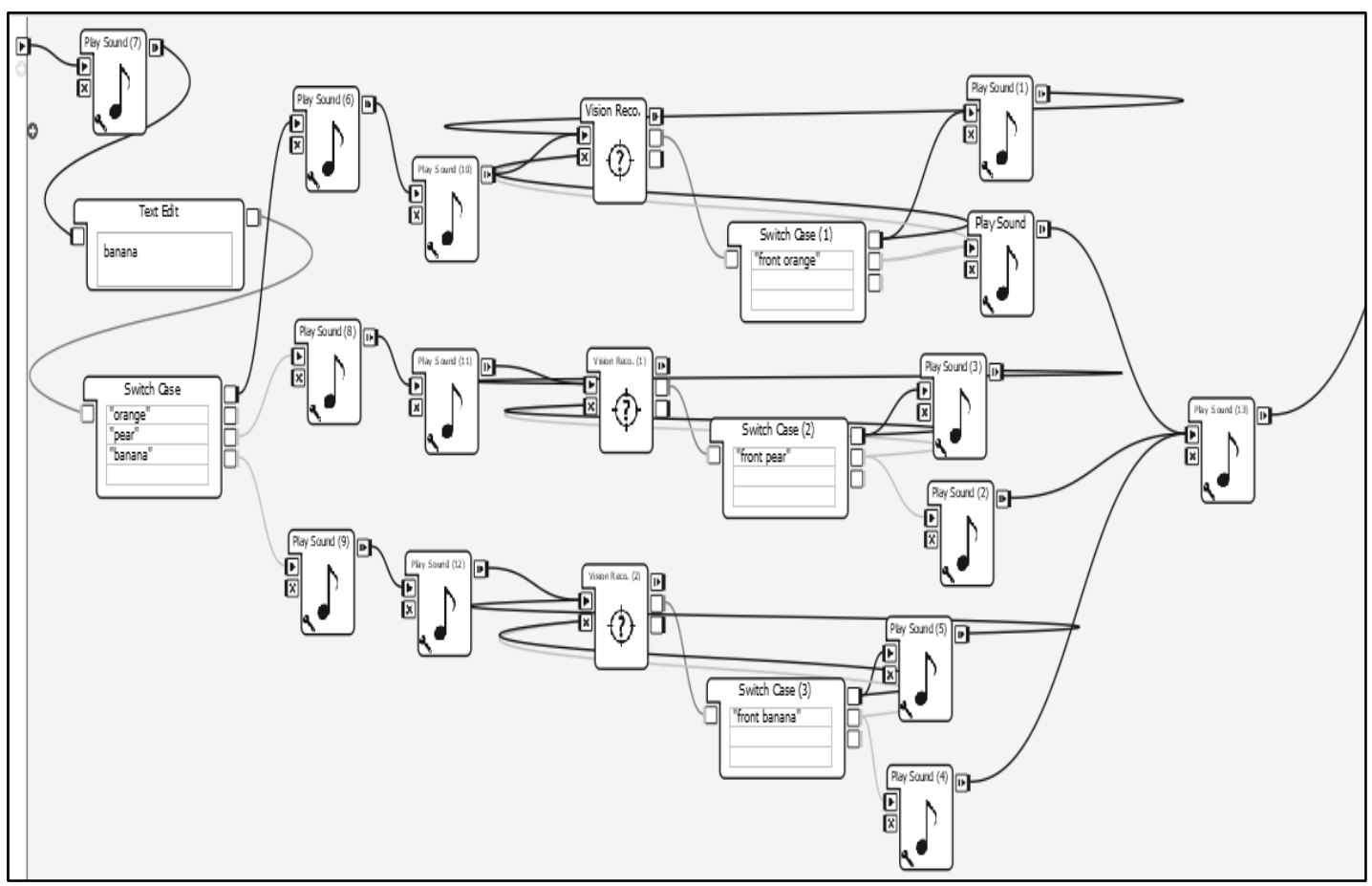

Figure 5. Fruit recognition program 


\subsection{Math Exercise}

Another program that was developed for NAO was the math program. This math program can teach children the basic operations in mathematics (addition, subtraction, multiplication and division). The program also makes use of a randomizer so that each equation that is performed by the robot is different. There is also another version of this program that allows for the user to input the numbers via speech. The robot can use voice recognition to understand the numbers from the user, so that they can be stored in its database for further processing. In either case, the numbers are processed and outputted to the user using the built-in speakers on the sides of the robot's head. All inputs and outputs are customizable, depending on the language that is required.

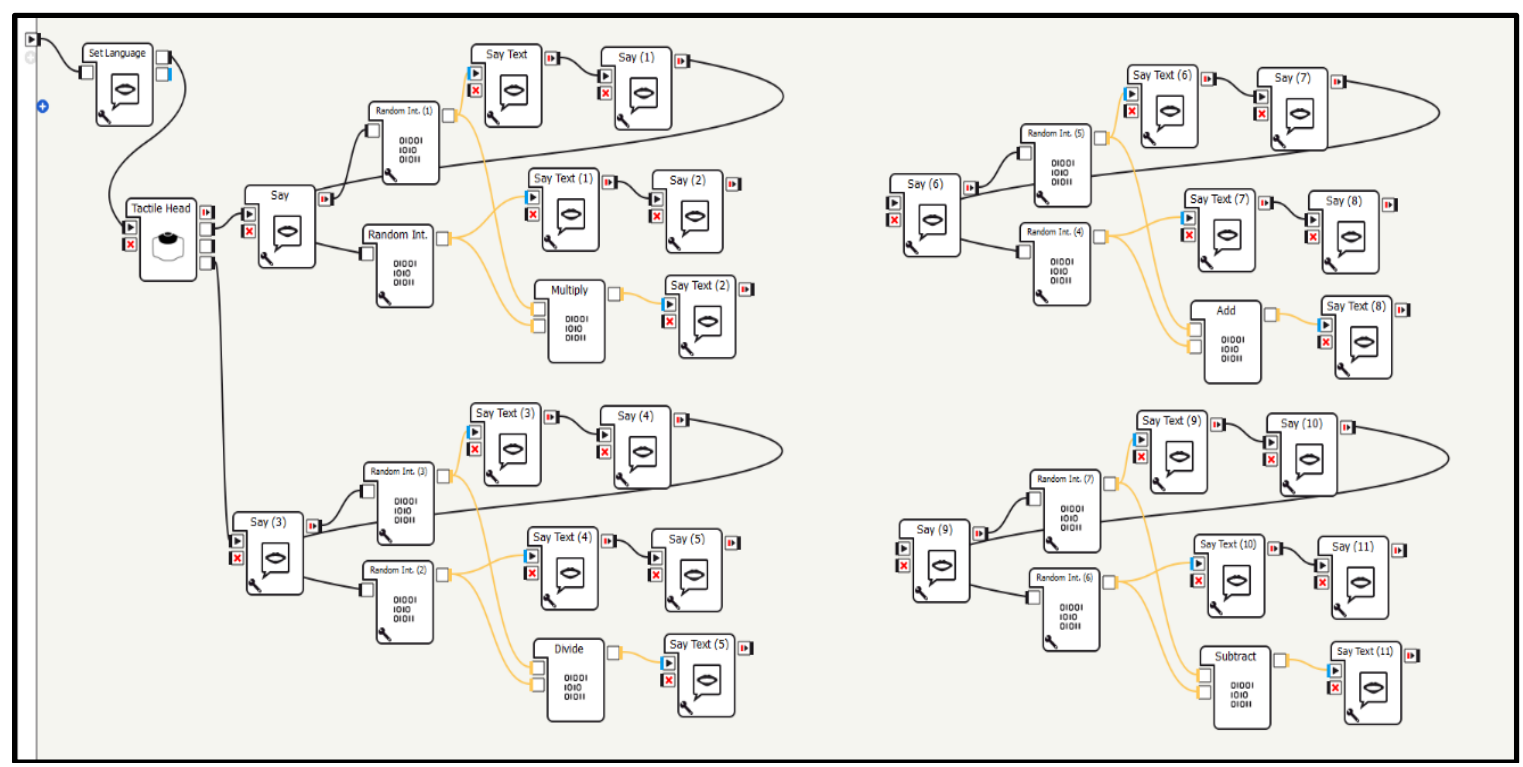

Figure 6. Math Exercise Program

\section{Results and Discussion}

All of the participants of this study were brought from the Nebras Autism Centre that is located in Al-Saham, Sultanate of Oman. There were 6 participants in total aged between $6-10$ years old (average age of 8 years old), four of which were male and two were female. All of the students and their caregivers were made aware about the experiment, and they all agreed for them to take place under the current conditions.

Autism cases are increasing at alarming rates. This is backed up by data from TACA (The Autism Community in Action), which has been shown that one in 59 children have been diagnosed with autism. This is a significant increase (78\%) over the last 4 years as mentioned in (Wainer et al., 2010). With increases in autism cases comes increases in the required funds needed by healthcare facilities to provide therapy for these individuals. Therefore, researchers, 
educators and parents of autistic children around the world are working together to develop the most suitable and effective teaching method to help autistic children. So far, robots and HRI have been shown to be one of the best teaching methods, mainly due to their playful nature.

Our results have shown that the students were very interested and engaged during the entirety of the experiment. This is in contrast to how they usually act in the clinic, where they usually do not give a response or are uninterested. This is also very different from the prediction of the professionals at the clinic, who thought that the children will be scared of the robot. The children also learned all of what the robot taught them, no matter what the subject was, and in a much shorter amount of time. In the clinic, the professionals had to reserve copious amounts of times to teach them the same things and they were usually not very successful. The robot definitely helped improve the children's emotional, social and mental skills, since their attitude was much more positive, they were much more approachable after the experiment and they interacted much more frequently with both the adults as well as each other.

\section{Conclusion}

Response This work focuses on developing interactive activities and materials, based on robots, that could help autistic children improve their social, emotional and mental skills. NAO has a very simple, toy-like face that allows it to interact with autistic children in a way that does not overload their senses. This is one of the most important phenomena that need to be taken into consideration when developing these teaching methods. With that being said, research on HRI is still on the rise in several different countries. According to the literature survey, the USA had the most research on HRI with ASD children (14 papers), followed far behind by England (3 papers) and Spain (2 papers). The results of this study showed that the children were very happy to play with robot and were quick to follow all instructions, without any problems. Also, it was found that the children had positive attitude regarding the use of robots as assistants alongside teachers. In addition, we examined very good improvements in the academic level of students in subjects like fruits, vegetables, animals, colors and shapes. They also learned the meaning of words and how to use them in sentences, which improves the students reading and communicational abilities. Some activities based on dancing and songs were also incorporated in the lectures to keep the children engaged and to keep the lessons fun.

Therefore, we encourage the clinics and the ministry of health in Oman to incorporate the use of these humanoid robots in future teaching and treatment methods of children with autism. More research also needs to be done on the use of other robots besides NAO in teaching children with autism. 


\section{Acknowledgment}

The research leading to these results has no Research Project Grant Funding from the Research Council in the

Sultanate of Oman, Research Grant Agreement FURAP/SU/17/004. The authors would like to acknowledge support

from the Research Council in the Sultanate of Oman.

\section{References}

[1]. Vellonen, V., Kärnä, E., \& Virnes, M. (2012). Communication of children with autism in a technology-enhanced learning environment. Procedia-Social and behavioral sciences, 69, 1208-1217.

[2]. Shamsuddin, S., Yussof, H., Ismail, L. I., Mohamed, S., Hanapiah, F. A., \& Zahari, N. I. (2012). Humanoid robot NAO interacting with autistic children of moderately impaired intelligence to augment communication skills. Procedia Engineering, 41, 1533-1538.

[3]. Robins, B., Dautenhahn, K., Te Boekhorst, R., \& Billard, A. (2004). Effects of repeated exposure to a humanoid robot on children with autism. In Designing a more inclusive world (pp. 225-236). Springer, London.

[4]. Robins, B., Dautenhahn, K., \& Dickerson, P. (2009, February). From isolation to communication: a case study evaluation of robot assisted play for children with autism with a minimally expressive humanoid robot. In 2009 Second International Conferences on Advances in Computer-Human Interactions (pp. 205-211). IEEE.

[5]. Miskam, M. A., Masnin, N. F. S., Jamhuri, M. H., Shamsuddin, S., Omar, A. R., \& Yussof, H. (2014). Encouraging children with autism to improve social and communication skills through the game-based approach. Procedia Computer Science, 42 , 93-98.

[6]. Malik, N. A., Yussof, H., \& Hanapiah, F. A. (2014). Development of imitation learning through physical therapy using a humanoid robot. Procedia Computer Science, 42, 191-197.

[7]. Baron-Cohen, S., Scott, F. J., Allison, C., Williams, J., Bolton, P., Matthews, F. E., \& Brayne, C. (2009). Prevalence of autismspectrum conditions: UK school-based population study. The British Journal of Psychiatry, 194(6), 500-509.

[8]. Yousif, J. H. (2011). Information Technology Development. LAP LAMBERT Academic Publishing, Germany ISBN 9783844316704.

[9]. Yousif, J. H., Al-Hosini, M., Al-Sheyadi, S., Al-Ofui, A., \& Al-Sheyadi, M. (2018). Questionnaire of Using Humanoid Robot for Teaching and Learning Kids. International Journal of Computation and Applied Sciences (IJOCAAS), 4(2), $324-329$.

[10]. Yousif, M. (2021). Viability of Robots in Improving Autistic Student's Engagement and Happiness When Learning. Artificial Intelligence \& Robotics Development Journal, 26-42.

[11]. Yousif, J. H. (2021). Social and Telepresence Robots a future of teaching. Artificial Intelligence \& Robotics Development Journal, 1 (1), 58-65.

[12]. Adams, A., \& Robinson, P. (2011, October). An android head for social-emotional intervention for children with autism spectrum conditions. In International Conference on Affective Computing and Intelligent Interaction (pp. 183-190). Springer, Berlin, Heidelberg.

[13]. Ranatunga, I., Rajruangrabin, J., Popa, D. O., \& Makedon, F. (2011, May). Enhanced therapeutic interactivity using social robot Zeno. In Proceedings of the 4th International Conference on PErvasive Technologies Related to Assistive Environments (pp. 1-6).

[14]. Cabibihan, J. J., Javed, H., Ang, M., \& Aljunied, S. M. (2013). Why robots? A survey on the roles and benefits of social robots in the therapy of children with autism. International journal of social robotics, 5(4), 593-618.

[15]. Tacanow, 2021. AUTISM STATISTICS \& COST. Online resource. https://tacanow.org/autism-statistics/ [Accessed on 10 March 2021].

[16]. Dautenhahn, K., \& Werry, I. (2004). Towards interactive robots in autism therapy: Background, motivation and challenges. Pragmatics \& Cognition, 12(1), 1-35.

[17]. Robins, B., Dickerson, P., Stribling, P., \& Dautenhahn, K. (2004). Robot-mediated joint attention in children with autism: A case study in robot-human interaction. Interaction studies, 5(2), 161-198.

[18]. Robins, B., Dautenhahn, K., \& Dubowski, J. (2006). Does appearance matter in the interaction of children with autism with a humanoid robot. Interaction studies, 7(3), 479-512.

[19]. Kozima, H., Nakagawa, C., \& Yasuda, Y. (2007). Children-robot interaction: a pilot study in autism therapy. Progress in brain research, 164, 385-400.

[20]. Pierno, A. C., Mari, M., Lusher, D., \& Castiello, U. (2008). Robotic movement elicits visuomotor priming in children with autism. Neuropsychologia, 46(2), 448-454. 
[21]. Stanton, C. M., Kahn, P. H., Severson, R. L., Ruckert, J. H., \& Gill, B. T. (2008, March). Robotic animals might aid in the social development of children with autism. In 2008 3rd ACM/IEEE International Conference on Human-Robot Interaction (HRI) (pp. 271-278). IEEE.

[22]. Duquette, A., Michaud, F., \& Mercier, H. (2008). Exploring the use of a mobile robot as an imitation agent with children with low-functioning autism. Autonomous Robots, 24(2), 147-157.

[23]. Ravindra, P., De Silva, S., Tadano, K., Saito, A., Lambacher, S. G., \& Higashi, M. (2009, October). Therapeutic-assisted robot for children with autism. In 2009 IEEE/RSJ International Conference on Intelligent Robots and Systems (pp. 3561-3567). IEEE.

[24]. Feil-Seifer, D., \& Matarić, M. J. (2009). Toward socially assistive robotics for augmenting interventions for children with autism spectrum disorders. In Experimental robotics (pp. 201-210). Springer, Berlin, Heidelberg.

[25]. Stribling, P., Rae, J., \& Dickerson, P. (2009). Using conversation analysis to explore the recurrence of a topic in the talk of a boy with an autism spectrum disorder. Clinical linguistics \& phonetics, 23(8), 555-582.

[26]. François, D., Powell, S., \& Dautenhahn, K. (2009). A long-term study of children with autism playing with a robotic pet: Taking inspirations from non-directive play therapy to encourage children's proactivity and initiative-taking. Interaction Studies, 10(3), 324-373.

[27]. Lund, H. H., Pedersen, M. D., \& Beck, R. (2009). Modular robotic tiles: experiments for children with autism. Artificial Life and Robotics, 13(2), 394-400.

[28]. Costa, S., Santos, C., Soares, F., Ferreira, M., \& Moreira, F. (2010, January). Promoting interaction amongst autistic adolescents using robots. In 2010 Annual International Conference of the IEEE Engineering in Medicine and Biology (pp. 3856-3859). IEEE.

[29]. Wainer, J., Ferrari, E., Dautenhahn, K., \& Robins, B. (2010). The effectiveness of using a robotics class to foster collaboration among groups of children with autism in an exploratory study. Personal and Ubiquitous Computing, 14(5), 445-455.

[30]. Feil-Seifer, D., \& Matarić, M. J. (2011, March). Automated detection and classification of positive vs. negative robot interactions with children with autism using distance-based features. In 2011 6th ACM/IEEE international conference on human-robot interaction (HRI) (pp. 323-330). IEEE.

[31]. Shamsuddin, S., Yussof, H., Ismail, L. I., Mohamed, S., Hanapiah, F. A., \& Zahari, N. I. (2012). Initial response in HRI-a case study on evaluation of child with autism spectrum disorders interacting with a humanoid robot Nao. Procedia Engineering, $41,1448-1455$.

[32]. Giannopulu, I., \& Pradel, G. (2012). From child-robot interaction to child-robot-therapist interaction: A case study in autism. Applied Bionics and Biomechanics, 9(2), 173-179.

[33]. Dickstein-Fischer, L., \& Fischer, G. S. (2014, August). Combining psychological and engineering approaches to utilizing social robots with children with Autism. In 2014 36th Annual International Conference of the IEEE Engineering in Medicine and Biology Society (pp. 792-795). IEEE.

[34]. Costa, S., Lehmann, H., Dautenhahn, K., Robins, B., \& Soares, F. (2015). Using a humanoid robot to elicit body awareness and appropriate physical interaction in children with autism. International journal of social robotics, 7(2), 265-278.

[35]. Agosta, G., Borghese, L., Brandolese, C., Clasadonte, F., Fornaciari, W., Garzotto, F., ... \& Valla, M. (2015, August). Playful Supervised Smart Spaces (P3S)--A Framework for Designing, Implementing and Deploying Multisensory Play Experiences for Children with Special Needs. In 2015 Euromicro Conference on Digital System Design (pp. 158-164). IEEE.

[36]. Richard Margolin, Parent Perspective: The greatest investment any school can make. Online resource. https://robots4autism.com/author/richard/

[37]. Haje Jan, The Autism Solutions bot helps autistic kids. https://techcrunch.com/2016/09/11/autism-solutions/

[38]. Jeff Goodman, Robots, Engagement and Autism Spectrum Disorder Intervention. Online resource. https://robots4autism.com/press/robots-engagement-and-autism-spectrum-disorder-intervention/

[39]. Huijnen, C. A. G. J., Lexis, M., \& de Witte, L. P. (2017). Robots as new tools in therapy and education for children with autism. Int J Neurorehabil, 4(278), 2376-0281. 